\title{
Consumers as Mental Health Providers: First-Person Accounts of Benefits and Limitations
}

\author{
Carol T. Mowbray, Ph.D. \\ David P. Moxley, Ph.D. \\ Mary E. Collins, Ph.D.
}

\begin{abstract}
Community support programs are increasingly establishing paid service positions designated exclusively for consumers. Project WINS (Work Incentives and Needs Study), a hybrid case management-vocational program for individuals with severe mental illness, used consumers as peer support specialists (PSSs) to supplement professional roles. Semistructured interviews were conducted with PSSs about 12 months after their employment ended. They identified substantial personal benefits specific to consumer-designated roles (e.g., a "safe" employment setting with accommodations) and general benefits from employment. Problems described were just as numerous, encompassing attitudes toward assigned peers and costs to their own well-being. Critical commentary addressed program operations (structure, supervision, and training needs) and problems in the mental health system. The authors discuss the changed sense of self that service provider roles can create for consumers and suggest that mental health administrators provide anticipatory socialization for this service innovation throughout their agencies and ongoing supports for consumers in their new roles.
\end{abstract}

Increasingly, mental health programs are creating service delivery roles for people with serious mental illness. Often based on a rationale of self-help and mutual support, programs see the establishment of such roles as strategies for increasing the accessibility of mental health and community support services as well as for making services more sensitive and responsive to the daily living needs of people who are served. ${ }^{1}$

Hiring consumers as providers reflects a recognition that professionally credentialed and formally trained human service professionals cannot meet all of the needs of people with serious mental illness and that consumers themselves bring something distinctive to the service process. This distinctiveness can involve a willingness to undertake community support tasks that professionals are unwilling to perform, a personal understanding of the frustrations many consumers experience with "the system," a commitment to help people meet their basic daily living needs, or a motivation to work in flexible and nontraditional ways such as meeting in community locations and at times not bounded by the traditional workday. Augmentation of the behavioral health care workforce to include consumers follows from an expanding management literature acknowledging the value of

Address correspondence to Carol T. Mowbray, Ph.D., Associate Professor and Associate Dean for Research, School of Social Work, University of Michigan, 1080 South University, Ann Arbor, MI 48109-1 106; e-mail: emowbray@umich.edu.

David P. Moxley, Ph.D., is an associate professor in the School of Social Work at Wayne State University.

Mary E. Collins, Ph.D., is an assistant professor in the School of Social Work at Boston University. 
cultural diversity in organizations; that is, increasing creativity, problem solving, and adaptation to change. ${ }^{2}$ It has now been recognized that diversity considerations should encompass health status, condition, and experience-not just race/ethnicity, age, and/or gender. ${ }^{3}$ Because of all these perceived benefits and others, the National Association of State Mental Health Program Directors has endorsed hiring consumers as providers in public mental health systems. ${ }^{4}$

Although there are a number of ways of creating new and innovative helping roles for consumers, designating specific positions for consumer service providers is a common strategy, particularly in psychiatric rehabilitation. These roles have included case manager, ${ }^{6}$ case management aide, ${ }^{7}$ crisis worker, ${ }^{8}$ assertive community treatment team member, ${ }^{9}$ housing support specialist, ${ }^{10}$ supported employment coach, ${ }^{11}$ peer counselor, ${ }^{12}$ advocate,${ }^{13}$ and clinicician. ${ }^{14}$ Research on these designated roles has demonstrated that consumers do indeed bring a distinctiveness to them and that consumers as service providers can perform as effectively as professionals. ${ }^{15}$

Given the increasing interest in the creation of designated service provider roles for consumers, there is a pressing need to augment the knowledge of mental health administrators about both the positive and negative consequences of this type of role innovation. Previous research undertaken by the authors, ${ }^{11}$ as well as self-reports by consumer providers, suggest that while role incumbents may experience benefits, these roles can become problematic, especially when the sponsoring organization neglects to put into place viable support systems designed to help workers sustain successful role performance and develop professionally. Mental health administrators often find themselves in the position of creating these roles and in supervising personnel who are responsible for the effective performance of consumer providers. They need to be aware of human resource development implications to approach this innovation proactively and to maximize benefits for service recipients, the sponsoring organization, and the consumer service providers. Outcomes for employees and for the organization as a whole are enhanced in a working environment that differs from traditional settings in promoting intergroup relations among people who are physically or culturally different from the majority workforce. At the heart of such differences in working environments are differences in organizational cultures including leadership and administrative practices. ${ }^{2}$

This article examines the benefits and limitations identified by a group of consumers who served as peer support specialists (PSSs) in an integrated case management/vocational services demonstration project. The authors undertook follow-up interviews with 11 out of 20 of these specialists 12 months or more after their employment ended. Through semistructured interviews, information was gathered on how these consumer providers viewed the benefits resulting from their roles-both for themselves and for the sponsoring organization-as well as on their perspectives on the limitations of these roles. This article summarizes these consumer viewpoints, then discusses their implications for organizational and administrative support of consumers who are placed in roles as service providers.

\section{Background}

Project WINS (Work Incentives and Needs Study) was a 3-year research demonstration project funded by the Substance Abuse/Mental Health Administration's Community Support Program. Its purpose was to enhance vocational opportunities to eligible clients by integrating vocational services into case management teams. ${ }^{16}$ Vocational opportunities provided were individualized; the goal was to procure jobs of choice in the community, in independent settings, although more traditional vocational rehabilitation placements could be offered as appropriate. The community jobs could be transitional or permanent, dependent on the client's needs and desires. The amount of support and assistance also was individualized. Previous reports have demonstrated WINS's success in meeting expectations concerning the quantity of services, the characteristics of service recipients, and the numbers who obtained jobs. ${ }^{17}$ 
The major component of Project WINS's operations was the services provided by five vocational specialists (VSs) assigned to eight case management teams across two participating agencies. Each VS provided direct services to a rotating caseload of about 20 clients from the assigned teams. The VSs also worked with case management staff to provide case consultation and information about vocational opportunities to the teams. Clients also could elect to receive services from PSSs who were themselves consumers from the case management teams served. The PSSs worked with VSs as case manager extenders and also served as role models for assigned clients. The PSSs provided services to individuals as negotiated in the WINS intervention plans for those clients, for example, helping clients to prepare resumes, set up bank accounts, acquire clothing for interviews or work, or learn the bus system. PSSs also were responsible for developing and acting as facilitators for job support groups, producing a newsletter, and carrying out other informational activities for WINS. At any one time, between four and seven PSSs were employed at WINS. Typically, each PSS worked about 7 hours a week with 4 or 5 clients, but this could range from 1 to 10 clients. PSSs were paid at an hourly rate ( $\$ 6 /$ hour). Prospective PSSs were referred by their case management teams and then interviewed by the Project WINS program director. About 20 hours of training was provided over a 2-week period. (See Mowbray et al." for more details.)

\section{Method}

Semistructured interviews were conducted with consumers formerly employed by Project WINS as PSSs. The interviews were conducted in July 1995. A total of 21 PSSs had been employed by WINS during its operation. Attempts were made to contact 20 ( 1 was deceased). Of these, 2 could not be located, the whereabouts of 5 were known but they could not be contacted, 2 others were contacted but could not be interviewed because of scheduling problems, and 11 were interviewed. All interviews were held at one of the case management agencies in Grand Rapids, Michigan and were conducted by the first two authors.

The interview guide covered six major topics: PSSs' employment history, activities after leaving WINS, description of activities as a PSS, retrospective analysis of the WINS experience and its effects on their lives, recommendations for further development of consumer employment, and future career and educational plans. The duration of the interviews ranged from 30 to 90 minutes, with most interviews lasting approximately 1 hour. Interviews were taped and later transcribed.

Analysis of the interview data involved review of the transcripts, identification of themes, and subsequent categorization of the text from interview transcripts. This was an iterative process until consensus was achieved between the first and third authors.

\section{Sample}

The 11 interviewed PSSs consisted of 6 males and 5 females. One man was African American; the other interviewees were white. Ages ranged from 32 to 53 years, with a median of 38 . Tenure as PSSs ranged from "a few weeks at the beginning" for 1 person to the full $21 / 2$ years for 2 others. Within this range, 2 individuals worked 4 to 5 months, 3 others worked for about 1 year, and the other 3 worked for about 2 years. Of those interviewed, 6 were with the program when it ended and, for the most part, expressed disappointment at not being able to continue in their jobs. In addition, 2 others had left because they had other jobs or wanted other jobs with more hours. Of the remaining 3 individuals, 1 dropped out early during the training, 1 had difficulty coping with the responsibilities of the position, and 1 was asked to leave. (Although the latter individual could have been rehired, he chose not to be.)

There was wide variety in the type and extent of PSS work experiences prior to WINS involvement. Among those interviewed, 4 persons reported virtually no work in the past 10 years, while 
another person reported a long history ( 30 years) of full-time work in factories, hospitals, and street maintenance. Other histories included 2 persons with several years of work in skilled trades, another person who had his own painting/home improvement business, several persons with experience in health care and food service, 1 person with nursing experience prior to the onset of mental illness and subsequent work in sheltered settings, another person with 3 to 4 years of work in each of three different settings (grocery cashier, nurse's aide, and food service), and 1 person with some restaurant work.

\section{Results}

This section first presents the PSSs' descriptions of benefits to themselves and to the system as well as of costs and negative outcomes concerning their attitudes, personal problems, and boundary issues. This is followed by a presentation of the PSSs' suggestions for structural improvements, comments on supervision and training needs, and the problems they identified with the mental health system.

\section{Description of Program Benefits and Costs}

\section{BENEFITS}

Peer support programs are designed to be mutually beneficial to the consumer-worker and to the peer. In addition, benefits to the larger mental health system are anticipated. Evidence from the interviews suggested that many benefits accrue to the PSS, but benefits identified for the mental health system appeared to be more limited, at least according to the PSS perspective.

In terms of benefits to the PSS himselfor herself, many of the PSSs mentioned the very important and concrete benefit of having money ("I was able to do more things personally than I could do ... because of the extra income") as well as the reward of having a job ("This type of job was something that I wanted to do; it was interesting"). Several PSSs reported gaining specific skills, transferable to a variety of employment situations. One reported learning from the VS several ways in which to positively present oneself with an application and resume:

He [the VS] could make the worst-looking resume look so good. He didn't lie or anything else; he used different ways to state things on the application. For example, if you quit a job because you just couldn't stand it anymore, you are not going to put that down on your "app"- -something like, "needed a change," that sounds a lot better.

Another very basic skill was becoming reinvolved in the routine of work: "It was scheduling; you have to be there at 9 [o'clock], you have to be there at 10, and getting used to that again." Other descriptions focused on the interpersonal skills necessary to attain and keep a job. For example,

I think I became a lot more assertive person. I am willing to communicate my emotions.... It helped me get along better with people ... and I learned a lot from being more assertive instead of being aggressive. It gets you more places.

Another PSS talked about learning how to better handle anger and frustration on the job: "It taught me about me, and it taught me that sometimes it's best to walk away and cool off." He related a situation at his current job in which the boss's son was handling him unfairly. He was able to talk to someone else about this and go back to his job. Another PSS spoke about the effect of his WINS experience on how he supervises others, that he learned "patience ... and just how to talk to someone without offending them and [to] correct them."

Other benefits related to WINS employment included experiencing it as a safe and positive work situation. These feelings contrasted with prior difficulties, particularly from stigmatizing attitudes. 
One respondent who had worked as a nurse stated that "one of the reasons WINS was so nice" was because in her earlier work, the other nurses were aware of her mental illness and "it was easy for me to feel defeated around people [who] were not psychiatric patients." WINS involved peers who "were all in the same boat":

Everyone had a different interest, but we were all starting from the same point ... so we had kind of open communication and good incentives, low fear level, [and] low judgment level because we were all going through the same experience.

Similar sentiments were espoused by others: "[It was a] nice way for me to have a part-time job, and more of a sheltered environment, where I am not out of the mental health system, I am still in it." One woman who left feeling she could not make enough money still stated,

It started me on a path to a solid work record. . . I I didn't have enough confidence that I thought I could work anywhere. I thought the real world was some kind of jungle, and [I] just couldn't make it through it. But it turned out that I had a lot of skills and knowledge that I wasn't even using. It was just there waiting to be tapped into. It was there.

Another PSS also described how WINS got her involved again in the world of work: "It was like a stepping-stone for my other jobs ... and I think [the program manager] thought I did pretty good."

Some comments suggested that the program offered challenges that were manageable and not found in a sheltered work setting, thus providing a normalizing experience. For example, "We traveled [in] snowy weather, we traveled [in] rain, we traveled in hot sun-and I think that's good for people. The monotony of always being in a controlled environment ... gets pretty blasé." Another discussed feeling some stress about presenting information on her cases to a "whole group of social workers," but "you work through that... I think everybody did... . Those kinds of things are kind of good for you, I think, if they're not too stressful and you volunteer to do them."

WINS also was seen as a more secure work experience. One PSS noted that although he had several hospitalizations, this did not cause him to lose his job with WINS: "I did not say, "To heck with it, I am done with it,' you know, move on to the next thing. So, somehow it drew out of me the ability to continue."

Several described the positive experiences they had in receiving feedback from staff at the agencies: "They kept praising me all the time that I was doing so well with their clients and stuff. And I kept saying that made me feel really good that I was doing that well." "The ... team really gave me a lot of support when I was there-peer support. They thought it was great that I was working."

Just to give an example, there was this one client [who] was real paranoid and said once, "I think I'm going to do some heavy hunting tonight." And right away, a red flag went up. I called [the] team, and they got right on it, and then afterward they thanked me for informing them of this incident.

For a few individuals, involvement in WINS also provided some career direction. One PSS wanted to continue in a helping profession, either social work or youth services: "I realized that I enjoy working with people, and I feel like I have something to offer somebody-some encouragement, after being through the system myself." Another did seek employment in the mental health field, but despite disappointment, noted that the program gave him "some visibility within the rehabilitation community and within the mental health community. And that was fun and good."

Several PSSs noted benefits of personal growth, specifically, increased knowledge about oneself, initiative, and perseverance: "It put me in contact with just what I was dealing with.... It was not just about working with others who shared a common illness, it was about learning why those people fail, why I fail." "It made me rely on myself a little bit more." "[It improved] self-esteem-both [of] the people that I served and my own." "I became more concerned about people's problems and seeing how they react to certain things." In addition, several individuals mentioned feelings of selfsatisfaction derived from helping others: "That program gave me the opportunity to help people, and I enjoyed that." "It made me feel like I was doing something worthwhile." "[A peer] called me up the 
day I left [and said], 'I'm really sorry you left because you were the best person to help me.' And that made me feel really good."

Finally, there were some benefits gained that were specific to being involved with other PSSs. Most expressed positive feelings about their fellow PSSs and, in some circumstances, continued their relationships with them: "Almost all the peer support specialists, I have seen or talked to on the phone or run into at restaurants or something. And they're just still as friendly as they ever were. It's like meeting old friends."

For the most part, most PSSs were hard-pressed to identify any perceived benefits to the larger mental health system. A few commented that the program provided some concrete benefits for people and that it provided more resources to the agencies: "I think it created more jobs." "I think it took a lot of the pressure off, [with PSSs] to go and do the things, like fill out the paperwork and stuff for people on SSI [Supplemental Security Income]." A few PSSs also noted that WINS served to positively alter attitudes toward the abilities of persons with mental illness, in effect, breaking down stigma: "I think they learned that some of the PSSs could really do a lot more than they thought they could do. ... They sat there and told me they were really surprised at how well I did."

Finally, one person noted that the demonstration program institutionalized the concept of peer support in the local area: "If nothing else, the peer support concept is in the system at [rehabilitation agencies], where people can work, and I think it's good."

\section{COSTS OR NEGATIVE OUTCOMES}

As much as they identified benefits of the program, the PSSs also identified problems, sometimes on the same topic. For example, concerning attitudes toward their assigned peers, several PSSs made positive comments: "After I got to know the different ones, I liked all of them, really. They all had some good qualities about them." One expressed admiration: "They [peers] were ... trying to do something for themselves, keeping themselves busy, finding jobs for themselves. Whenever they were offered something, they did it." Other PSSs observed problems but commented on them in an objective fashion: "Certain ones had problems with being in debt." "Most of them were real enjoyable.... I think maybe a few times I picked up feelings from people that they wished they could do it by themselves without help or frustration."

I never judged them. I just thought they had problems like everybody else... They're drinking and partying and doing all this other stuff 'cause that is what they mostly do because they got so much time on their hands if they aren't working or something. That's what they do, and then they get kicked out of their places.

More often, problems were identified that irritated the PSSs because the behaviors directly affected them and their ability to do their jobs, for example, clients who were not cooperative: "Well, there was one woman in particular [who] was very hard to reach.... She didn't let out much information about herself ... kind of secretive and real, real planted." "I don't think they really understood why we were there. It was kind of like we were the staff. ... It was a little scary to go to some of those houses, but some of them didn't know if they wanted to see us."

PSSs were particularly bothered by characteristics and behaviors that seemed contrary to the intent of the program and to their own work ethic. For example, "Well, [with] a lot of them, you wouldn't even get to first base; you wouldn't even get together with them." This produced anger and frustration: "They didn't show up or came real late; that frustrated me." "Some of them didn't want to work, and that just ticked me off totally." A need to distance and separate themselves also was expressed: "I don't want to sound mean, but they had a lot of psychosis and a lot worse problems than I had. I had it more together than some of these people." Feelings like these are common for any staff member working with difficult-to-serve clients. Perhaps for the PSSs, they were intensified because they worked with others like themselves or because of their lack of training in human services. 
While the PSSs enumerated a substantial number and variety of personal benefits from their positions, these were not attained without costs to their well-being: "It was the best job I've ever had, but it was also one of the toughest." A frequent comment concerned job stress-most of it minor, but some of it more troubling: "There was a lot of stress on that job. ... If I couldn't talk with [professional staff], sometimes I would come and take it home with me."

The stress seemed to come from a variety of sources. One source was disappointment over their own performance: "I wish I would have done a better job, but I didn't understand everything about it." "I wasn't the best. I could've maybe had some more training." This disappointment produced some negative feelings: "I thought, well, too bad they don't respond, and what did I do wrong? I felt that guilt again." One PSS's comments were quite descriptive:

I was sort of negligent in some of my responsibilities. Sometimes, I wouldn't show up for meetings or something or wouldn't call my clients, just whatever. Part of it was my own fault. ... Well, when I first started, I was new at the job and I didn't know exactly [that] I needed help to learn how to be a PSS [and] organize my time. To know how to talk to people, that is important-what kind of things to talk about with your clients, asking the right questions.

The implied lack of understanding about how to do the job is evidenced clearly by this quote:

I used to pray ... that God would give me wisdom to do the job, and He normally did. I used to pray, and then I would have the right things to say to people and be more able to solve their problems in a way, give them direction.

Also implied was a lack of support from supervisors and administrators:

What they told us was that we couldn't talk about [our work] with anybody except them, so then when they weren't available, then you tried to deal with what kind of problems [clients] had or what you could do to help them.

PSSs also worried about their responsibilities:

A couple times, the interview didn't go good or something about school didn't work out ... and [clients would] be angry.... And I thought, "What do I do? Do I try and bring them back? Who's liable in this situation?"

There also were some experiences of being given too much, or inappropriate, responsibility:

And what was kind of hard on me was I was ... going through some of my own things. And then they wanted me to help her [another PSS] too, and I felt kind of bad when I had to talk to her. I kind of felt that was the supervisor's role. I mean, the supervisor had me doing it.

One PSS said he left his job in frustration, shortly after starting it, because he never figured out what he was supposed to do. He commented sarcastically, "One thing I learned, if you find out you are going to have a job that was being paid to be nice to somebody, don't take it. Well, that's a farce. What kind of a job is that?"

Finally, for some, expectations about a career path and working in a professional capacity were raised but not fulfilled, especially for those whose jobs ended when project funding ended: "I began to look at it as a place from which to expand. And then at the 2 1/2-year mark, the rug got pulled out [from under] me." This individual was offered a volunteer position doing his PSS work, which he strongly resented:

Now, the vocational specialist at WINS moved right over to a vocational specialist position ... and then offered ... me an unpaid position to run the same stuff I was doing at WINS. ... They're getting paid, why ain't I getting paid? Hell with that! No thank you, see, ... it was demeaning! It was demeaning to me to think my job was important, I was a valuable employee ... and then to be told there is no room in the budget-you would be unpaid. 
After that, he was told about a paid position at another agency, which also turned out badly: "I was referred there by the coordinator of WINS. It was a dead end! I never got an interview! I never got an application! I got the run-around!"

Boundary issues encompassed personal issues, attitudes toward assigned peers, and friendship relationships. PSSs were recruited because they were clients of the case management agencies. As long-term clients, it was likely that they might be familiar with the peers assigned to them and that they would have much similarity, empathy, and rapport with those they were serving. These are conditions likely to promote friendships, and they did: "He was a pretty nice person. I enjoyed being with him . . . socializing with him. And I met him through this program. We are personal friends now." Yet, traditionally in mental health services, providers are restricted from developing any relationships with their clients. Friendships are seen as unprofessional, perhaps unethical. Some PSSs were able to maintain these boundaries, as evidenced by their answers to questions about being friends with their assigned peers: "They weren't really my friends. We were just associates because of the program." "No [not friends], probably because I had to go back to the rest of my life, to school, work, and stuff, and I didn't have time." "Sometimes, [friendship things would come up], and then I would say that I can't talk to them about that because that's not my place." More often, however, the PSSs did establish friendships with their assigned peers. Asked whether this caused any problems, two replied, "Yeah, it did a little bit. But I was kind of afraid I would say something that would hurt their feelings or something" and "Yeah, once in a while, I would do things more as a friend than as [a] PSS. ... I tried to stick to the rules of the PSS. . . [The problem was] how to draw the line." As a friend, the husband of one of these clients tried to borrow money from this PSS. When she said no, she then had trouble getting along with the client in her PSS role. Another PSS became friends with an assigned peer, Joe, who had problems that expanded beyond vocational issues. The PSS met with Joe several times to talk. His billing for these hours, however, was disallowed as beyond the scope of his employment. The PSS then cut down his contacts with Joe, but Joe responded by calling his house all the time. The PSS observed,

I don't think we should have been ever giving out our personal phone numbers to clients. Nobody else in the profession does it; why were we supposed to do that?... That was a valuable experience, though.... It taught me that I've got to draw lines, and I got to stick to them, and I can't back off, because if I back off, it will come up down the road.

One PSS dealt with the friendship issue by trying to separate out her paid PSS time from friendship time. Unfortunately, this strategy did not work very well:

I would just say, "No, we cannot discuss this right now because this isn't a part of your meeting or your time with me" ... and at first she got really mad. ... She felt I was crowding in time spent with her.... I kept telling her... now you are not just the only one.

Her other assigned peers also had difficulties with this approach: "They would say, 'Well, I want to talk about it right now.' And I said this is not the place and this is not the time. And it was like, 'I want that time right now." "Maintaining boundaries was a complicated issue. PSSs experienced many situations in which separating themselves from their peers clearly seemed undesirable, and friendships appeared to promote positive results.

I would get together and see my clients [socially] every now and then together. And I got in trouble for that. ... But I didn't see anything wrong with that. ... But somebody told me that wasn't called for, so I stopped doing it. But I had a lot more response with people [when we did this] because they wanted to get to know each other.

The complexity of differentiating between friend and worker was clearly articulated by this PSS:

There is a fine line where you can be a friend and you can be a helper-very difficult. Because you can be involved with people, but there is a point where you can be too involved, where you get all worked up and think that you have to be there so you can help that person. 


\section{Critical Perspectives}

The PSS interviews provided, directly and indirectly, much commentary on the operation of the program. Comments related to three areas: structural improvements, supervision and training needs, and the larger mental health system.

\section{STRUCTURAL IMPROVEMENTS}

Most frequently mentioned as concrete suggestions were changes in the hours of employment and the amount of compensation. Several PSSs felt that because of the limited number of hours and the pay rate, the position did not provide enough to meet their needs: "I couldn't get enough hours. I wanted more hours [20] because I wanted more income."

Many expressed problems over the hours being quite variable and the activities spread throughout the week so that work was conducted in several small increments. Others thought that the position should pay more than its $\$ 6$ hourly rate. One PSS commented on the discrepancy in pay between the professional staff and the PSSs: "Her amount, and you got us with the other amount, and there is, like, a big discrepancy there. Especially if we are doing about half the work or more."

Several PSSs made suggestions for improving WINS's services to recipients. A simple recommendation involved more frequent contact between PSSs and peers: "Just keeping tabs on them more than once a week, calling them every day." Those who expressed frustration with the peers' seeming lack of willingness to work subsequently commented that the program might do better screening: "I would make sure, too, that they really want to work, that they are interested." "I would want to be looking for people who somehow wanted out ... because to me that's kind of the only way to reverse things."

Others focused their comments on hiring better PSSs, specifically those with some work successes and without recent substance abuse or mental health problems:

Make sure he has held a job himself for a while, and back up what he is saying ... and have a checkpoint, see how he is doing with these other people.... Because I felt like there [were] a few PSSs [who] weren't qualified to help another person because they were so sick themselves. And they come across pretty angrily.

[Recruit] people [who] didn't drink on the job or smoke marijuana, [who] weren't in the hospital for a while, [who] could control themselves, and [who] were good dressers and were clean, and not slobby; good examples, more or less.

Several others focused on the following: "See if they could match me up with someone who would have the same interests as me or [who] I would be helpful with." This same PSS also commented that, in addition to better matching, he would have benefited from more information on the persons assigned to him:

It was more of, well, "You'll take this guy here, without knowing anything about [him]." . . [There should be] something where the staff person, myself, the specialist, and the person who is going to get the help meet together and talk about what is going on and what we are going to do here.

Another major area for structural improvement suggestions involved developing better employment opportunities and more information about them, along with activities to allow peers to demonstrate potential.

Only thing I could say that might be done a little differently is there were a lot of job opportunities that the voc[ational] specialist didn't always relay to me. A lot of the clients didn't get the information as far as certain jobs were concerned. A couple of them were disappointed that they didn't get a job through the program.

I think [clients] should be able to show their potential . . . kind of explore their strengths and weaknesses, and that is something that WINS didn't have. I think that WINS would have been more effective if [it] had more ways of exploring people's abilities. 
Finally, one PSS suggested that social activities be a part of the program: "Where [clients] get together and become social. I think if [people are] going to work, they have got to get some social lives in so they don't get overloaded with work."

\section{SUPERVISION}

Supervision had several components: a 1-hour weekly meeting with all the PSSs and VSs; individual weekly supervision with a VS to report on activities of the previous week, receive information, and obtain new assignments; and a meeting with the program director, as needed, to discuss problems with hours, schedules, evaluations, and pay raises. The majority of the PSSs indicated that they liked their supervisors and made positive comments about them such as "friendly," "nice to work with ... maintained a real positive approach to work," and the following: "She always knew what was going on. ... I think it was a well-run office." But the supervision appeared to have been low key: "It was good supervision. I enjoyed talking with [the supervisor]. He was pretty lenient on a lot of things." "I talked with [the supervisor]. I can't remember what we talked about, but I knew her." "The supervision was mainly, like, I don't remember a whole lot about that. We were mainly on our own, I think. .. . They let you call them. They were there to answer your questions."

Several PSSs commented that supervision focused exclusively on tasks rather than on any personal development issues: "It just wasn't part of the plan. It wasn't about that [the PSSs' own plans]. It was about getting people jobs and training." This comment might suggest that supervision was superficial: "[The supervisor] did say, you're doing good, you're doing great. He was encouraging me, but he didn't get to the root of the problem. I was more or less taking my work home with me." Concerning boundary issues, one PSS said, "I think they said you had to be careful that you don't get too emotionally involved." As seen in the previous subsection, these issues actually were much more complex than suggested by this simple piece of advice, which probably was not specific enough to be helpful to the situations with which PSSs were dealing.

Few of the PSSs could remember the specifics of their performance evaluations. One thought it was "every three months . . . in relationship to pay increase. . . It was like two or three pages." Another said, "I think they have records of my monthly eval[uation] or whatever." The few PSSs who made more detailed comments about their supervision were quite critical about the frequency of contact, amount of support, and competency of their supervisors: "I don't think [the supervisor] dealt with the mentally ill that much."

I don't think it was run right, to tell you the truth.... [PSSs] should have had more support from a trained staff ... in making sure that they don't come across too strong or too harsh with patients.

[The VS] wouldn't call me back when I called her to try to get help on how to deal with this person. So, she left it all up to me on how to guide this person in the right way, and then I'm not sure if I did the right thing.

Some PSSs talked about differences in education or status between themselves and the VSs. These feelings might reflect their own personal issues or might reflect how seriously they were taken by the professional staff. When asked whether the staff treated them like fellow professionals, PSSs said the following: "Yeah, kind of in a way. I always felt like they were above me because they had more education." "We had differing views about things. And I would voice my difficulty, and then I would just kind of have to bite my tongue and eat it as far as what the result was."

I would have conflicts with [supervisors].... They don't like some of my ideas.... They wouldn't say yes or no or write it down.... I think that they didn't value me personally... When I became a PSS, I was asking them some really good questions, like maybe scary questions.

Some PSSs insightfully pointed out mutual problems with supervision:

Toward the end, I needed more supervision. Not that they didn't try to give it to me, but sometimes I would just take things upon myself and just handle it that way.... I myself have got to learn to ... get help when I need help and not just when somebody's offering help. 
I think I was treated well, except I didn't know how to use supervision personally. But that was my fault; I could have went to him. . . The supervisor I have now has a lot more supervisional skills than a voc[ational] specialist did. ... The [PSS] fear was there ... of supervision.

Training is seen as an area closely related to supervision. Employment problems can reflect either poor initial training or deficits in supervision. Surprisingly, given the newness of their positions and the fact that most PSSs lacked experience with human services, it appears as though the training component of Project WINS was minimal or, at least, left little impression. One PSS described training as follows: "I was trained as I went along, kind of." Another said, "We had to read a lot of material on helping people." Several were critical of the training they were given:

I think they should have more of a staff intervention at the beginning instead of just bringing all the clients [PSSs] together and having a meal and saying, "Okay, go out and help your fellow sufferer in the community." Because they don't give you a base on what to go by. It's like saying, "Here's a job-do it, but I am not going to tell you how to do it." ... They just sort of left it up to us.

More training on how to communicate better with people would be helpful. Be able to really communicate well with the clients, know where they are coming from and what to say and when to draw them out and everything.

\section{PROBLEMS IN THE MENTAL HEALTH SYSTEM}

The interview had not asked for critiques of the mental health system. However, three of the PSSs spontaneously provided perspectives on this level. For these individuals, their PSS experiences made them realize some of the larger problems in the mental health system and in the community. One problem highlighted was lack of resources. When asked what effect involvement with WINS had on him, this PSS answered,

I think it sort of had a negative effect, to tell you the truth. Well, I seen there wasn't a system set up to handle this, all these people who needed all these different resources. And I wondered why other places weren't doing it.... Nobody was helping them. . . Because you can't get a job unless you get transportation to and [from] work. And if you don't have a place to live, I don't know what that means.

Another PSS talked about the disincentives to working created by policies of SSI/SSDI (Social Security Disability Income):

It was therapy for me to work. How do you tell someone that, [who's] been sitting on their duff for two months, or two years, or longer? How to tell someone [who's] got it made in the shade collecting social security, and you tell them work's good for you, but your benefits are going to get cut because you're going to be working?

Another PSS commented that he wouldn't work in direct mental health services again because the whole field was too crisis oriented. This contributed to a system that just did not work:

And sometimes it is so hard to separate what is insanity, what is the system, and untwisting it, kind of pulling it apart and saying, it's not, just, not all about the insanity; some of it is the insanity of the system.

This same PSS also talked about stigma concerning mental illness, which contributed to people being "stuck" in the system:

The general public still has a conception about mental illness. That stigma is there, there, there, and I know that real well because I live with it. And in dealing with people [who] I deal with daily who have known me for 10 or 15 years, they can't forget me. They don't forget the antics that I have pulled. I can get as healthy as the healthiest person in the world, if such a standard exists, and it won't make a difference.

Stigma also is inherent in the cognitions of some clients:

You think that you can change the world; well, you can't change the world overnight, anyway. You think you can get some of these guys ... off alcohol or drugs ... and get them back to work.... Then they sober up, and maybe they are not taking drugs anymore. All of a sudden, they are the same type of [people] that 
nobody would hire anyway. ... No boss is going to hire them. So what do you do with those types of people? They're just stuck in the mental health system.

Another reflection of how the system was stuck was the fact that WINS ended and many PSSs wound up unemployed and went back to being clients in that system:

Because the system takes care of itself, I believe. If you look through the records of those who were consumers as opposed to those who were not consumers, you'll find that subtle discrimination.... The consumers were kind of absorbed back to where they belonged ... whereas those who were [professionals], they seemed to just kind of shift over and they found them[selves] another position.

These PSSs are indicating that some of the reasons for problems with WINS and with the operation of its PSS component were due to the way in which the mental health system was funded and structured as well as to societal discrimination and stigma toward mental illness.

\section{Implications for Behavioral Health Services}

The addition of the PSS roles was innovative; it expanded community support to include new forms of relationships (consumer helping consumer), created new helping roles, and achieved new types of outcomes (employment experience in human services). Although few system-level benefits were mentioned by the PSSs, the creation and implementation of peer support was perceived as increasing its legitimacy within case management services.

A significant benefit to consumer providers was that their positions stimulated personal and professional growth. A number of specific competencies reflected this outcome: vocational development and the mastery of core work skills, the enhancement of helping skills, a feeling of personal value and worth, normalization through the availability of a work routine, the acquisition of money, and the positive contribution this made to individuals' quality of life and standard of living. Many of the PSSs noted how service positions designated for consumers offered a safe and encouraging starting point for further independent employment.

However, these benefits must be considered in the context of the costs identified by the PSSs. Rather than dissecting these individually, it is more productive to see them as expressions of a metatheme of consumers' "changing sense of self," meaning that new roles create new conceptions of people. Role incumbents begin to view themselves differently, and people filling other roles (e.g., peers, treatment personnel) may experience considerable ambiguity in relating to them even though the persons have not physically or materially changed. They are different as a result of the creation of a new role.

The idea of a "changing sense of self" helps provide a better understanding of the personal negative consequences identified by the PSSs. They reported feeling considerable stress, feeling inadequacy in performing new duties, not feeling skilled enough, and not feeling confident in how to do their job as a PSS. The interviews suggest that the PSSs found themselves in a gray area in which they were neither consumer nor professional; they were something else. Such feelings were accentuated by the new relationships they established with their peers, some of whom were former friends, and by the new relationships they established with their colleagues and supervisors, some of whom were their former treatment personnel. This situation creates considerable potential for marginalization.

On one level, administrators may simply resolve these issues by concluding that the PSSs were not selected well or that they were not satisfactorily oriented and trained. Management literature, however, suggests that these are indicators of role change, the fallout of moving from one role to another without anticipatory socialization of all the principal stakeholders involved in the transition-including peers, supervisors, administrators, and consumer service providers. ${ }^{18}$

It is telling that the consumer service providers perceived an absence of strong support by nonconsumer staff. Not only were these actors seen as lacking a supportive posture, they also were seen as failing to treat the PSSs as professionals, sometimes assigning what was perceived as trivial work, 
lower level responsibilities, or tasks that bona fide professionals did not want to undertake. Furthermore, supervisory recognition and attention to boundary issues, which were so critical to these new employees' positions and performance, were almost completely absent. Certainly, we cannot rely on selection, orientation, and training of the consumer service providers, in isolation from other organizational actors, to counteract forces that reduce the value and standing of consumers in provider roles. Analogizing to multicultural considerations, an assimilation strategy that puts the burden of change totally on the employee who comes from a diverse background is antithetical to positive individual or organizational outcomes. ${ }^{2}$ Broad, systemic approaches need to be undertaken within the sponsoring agency to facilitate the success, nurturance, and performance of consumer service providers.

The data indicate that role change and its accompanying change in sense of self have risks that are borne primarily by the consumer who chooses to enter into a new role. If the sponsoring agency is to facilitate the changed sense of self, then it must establish a set of supports that counteract marginalization and strengthen the value of the new roles. This means that stakeholders are willing to enter into new relationships with consumers as service providers and to adopt new attitudes, values, and patterns of behaviors, including supervisory and administrative ones, in support of the new role incumbents. The selection, orientation, and training imperative has to apply to everyone in the service system and not merely to consumer service providers. Key stakeholders must recognize that this innovation involves a "changing sense of organizational self," with new concepts of human resources, new definitions of professionalism, new ways of supporting people, and new means of valuing performance.

Behavioral health administrators should not tinker with consumer-provider roles until they build an organizational consensus on their value and on the contributions that can be made. Building this organizational consensus involves what we mean by anticipatory socialization. Furthermore, once such a consensus is achieved, there must be adequate preparation of the entire workforce and ongoing supports to sustain the innovation. The following steps might be helpful. These tasks correspond to recommendations advanced by $\mathrm{Cox}^{2}$ in a five-component framework for managing cultural diversity requiring leadership, organizational assessment, training, personnel management systems, and follow-up to ensure continuous improvement.

1. Administrators need to build consensus on whether to create these roles and how they fit into the human resource development structure of the agency. They should not wait to make changes or even adjustments to this structure after these roles are created and filled. They also need to decide in advance how they will recruit consumers to fill these roles, support the development of the new role incumbents (through performance expectations and reimbursement mechanisms), and create career and advancement opportunities for people as they master their initial tasks, assignments, and responsibilities.

2. Supervisors need to build consensus on how they will supervise consumer service providers. Comments from informants in this study implied that supervisors were low key, focused on task accomplishment and performance, and not attentive to personal conflicts and training needs. This approach appears to be problematic since it is not geared to helping consumer service providers to develop. A developmental supervisory framework underscores where workers are going and how they are mastering their current roles and responsibilities while moving toward those ends. From the perspective of the informants, supervisors did not expect them to make any movement within the organization and did not expect them to attain any meaningful longevity. This is not the fault of the supervisors. It is, however, a negative consequence of an organizational failure to establish a meaningful and explicit framework of supervision designed to help consumer service providers to (1) master their roles, (2) be fully integrated into and accepted by the organization, (3) develop professionally, (4) establish a career direction that they desire and that makes sense to them, and (5) navigate this career direction and address the developmental issues that support or reduce effective performance. 
Whether the consumer service provider wants to pursue this career is a personal choice; it should not be made by the sponsoring organization "in the best interest" of the consumer. Whether the consumer service provider is successful is in part the responsibility of the consumer and in part the responsibility of the sponsoring organization. The organizational message to the consumer service provider must be that we value his or her contributions and distinctiveness and that we will support the individual in his or her quest to develop a "new sense of self."

3. Colleagues need to build a consensus on what is meant by professionalism. The culture of human services places a premium on education as well as on certification and licensure, yet in practice, particularly in psychiatric rehabilitation, the personnel of human services is increasingly transdisciplinary. Despite the influence of managed care's equation of quality with formalized schooling and credentialing, people with a variety of educational, skill, and credentialed backgrounds are making important and vital contributions to community support and psychiatric rehabilitation. Consumers as service providers challenge our credentialing systems. They can define new ways of thinking about professionalism through the introduction of task and role competency, life experiences, and personal qualities into the matrix of credentialing. This matrix can offer a broad yet accountable way of defining entry-level professionalism as well as career progression that is inclusive of the strengths, gifts, and assets brought to human service roles by different personnel.

4. Service recipients need to build an understanding of the changing roles of their peers and probably relinquish the idea that friendship is the defining attribute of their relationship with consumer service providers. A basis in friendship is made ambiguous or even nullified by the creation of the new role. Certainly, a central theme emerging out of interviews with informants was their confusion about how they were to relate to peers who are now actually their clients. Building this understanding among service recipients and consumer service providers by raising awareness, education, and small group discussion can facilitate the transition of consumers into either new roles as service providers or new ways of relating to the services these new providers offer. Perhaps titles should not incorporate "peer" unless consumer-providers are working in self-help settings; otherwise, employed as staff, consumers no longer are true peers, and the label can contribute to the confusion expressed by service recipients and consumer providers alike.

The administrative aim of consensus building is to reduce the ambiguity that surrounds consumers providing services in designated peer positions. Anticipatory socialization means that administrative leadership does not wait for the organization's response to the innovation to establish the meaning, purpose, and function of these roles. Proactive administration engages people in a process of organizational development that supports the establishment of effective service delivery roles for consumers and that is sensitive to the consequences of these new roles, not only for other organizational stakeholders but also for the people who become consumer service providers.

\section{Limitations}

It should be acknowledged that this article was based on interviews with a limited number of consumers from only one geographical area. The diversity of the group reflected the demographics of that service population but certainly not that of the entire United States. Also, we were not able to interview nine of the original PSSs. While there is no reason to suspect that the opinions of these consumers would have differed substantially from those collected, there is no way of establishing this for sure. However, the authors feel confident of the validity of the opinions expressed because they are quite congruent with the sentiments from many other consumer providers found in the literature.

\section{Conclusions}

The experience of Project WINS indicates that even 2 years after employment as PSSs, consumer providers reported that their experiences contributed positively to their skill development and 
personal growth. As a "safe" employment role, that of PSS offered several advantages as a starting point for further vocational activity. However, the limitations of this role innovation have to be acknowledged. Administrators can minimize the costs to the consumer providers as well as to the rest of the system through proactive planning and consensus building that recognizes the personal and systemic transformations needed in response to the resultant changed sense of the self that occurs when consumers become service providers.

\section{Acknowledgment}

This research was supported by a grant (No. R18MH46081) from the Center for Mental Health Services, Community Support Branch, Substance Abuse and Mental Health Administration, to the Michigan Department of Mental Health.

\section{References}

1. Mowbray CT, Moxley DP, Van Tosh L: Changing roles for primary consumers in community psychiatry. In: Talbott JA, Browne J, Freeman M, et al. (Eds.): Textbook of Administrative Psychiatry: New Concepts for a Changing Behavioral Health System. Second ed. Washington, DC: American Psychiatric Association Press, in press.

2. Cox T: Cultural Diversity in Organizations: Theory, Research and Practice. San Francisco: Berrett-Koehler, 1994.

3. Kavanagh KH, Kennedy PH: Promoting Cultural Diversity: Strategies for Health Care Professionals. Newbury Park, CA: Sage, 1992.

4. National Association of State Mental Health Program Directors: Position Statement on Employment for Persons with Severe Psychiatric Disabilities. Unpublished paper, December 12, 1990.

5. Mowbray CT, Moxley DP, Jasper C, et al. (Eds.): Consumers as Providers in Psychiatric Rehabilitation. Columbia, MD: International Association of Psychosocial Rehabilitation Services, 1997.

6. Solomon P: Services to severely mentally disabled homeless persons and to emergency food and shelter providers. Psychosocial Rehabilitation Journal 1988; 12(2): 3-13.

7. Sherman PS, Porter R: Mental health consumers as case management aides. Hospital and Community Psychiatry 1991; 42:494-498.

8. Lyons JS, Cook JA, Ruth AR, et al.: Service delivery using consumer staff in a mobile crisis assessment program. Community Mental Health Journal 1996; 32:33-40.

9. Dixon L, Krauss N, Lehman A: Consumers as service providers: The promise and challenge. Community Mental Health Journal 1994; 30:615.633.

10. Besio SW, Mahler J: Benefits and challenges of using consumer staff in supported housing services. Hospital and Community Psychiatry $1993 ; 4: 490-491$.

11. Mowbray CT, Moxley DP, Thrasher S, et al.: Consumers as community support providers: Issues created by role innovation. Community Mental Health Journal 1996; 32:47-67.

12. Harp H: A Crazy Folks Guide to Reasonable Accommodation and "Psychiatric Disability." Burlington, VT: Trinity College of Vermont, Institute for Program Development, Center for Community Change through Housing and Support, 1991.

13. Mowbray CT: Benefits and issues created by consumer role innovation in psychiatric rehabilitation. In Mowbray CT, Moxley DP, Jasper C, Howell, L. (Eds.): Consumers as Providers in Psychiatric Rehabilitation. Columbia, MD: International Association of Psychosocial Rehabilitation Services, 1997, pp. 45-63.

14. Fisher DB: A new vision of healing as constructed by people with psychiatric disabilities working as mental health providers. Psychosocial Rehabilitation Journal 1994; 17(3): 67-81.

15. Solomon P, Draine J: One-year outcomes of a randomized trial of consumer case management. Evaluation and Program Planning 1995; 18(2): 117-127.

16. Mowbray CT, Rusilowski-Clover G, Arnold J, et al.: Project WINS: Integrating vocational services on mental health case management teams. Community Mental Health Journal 1994; 30:347-362.

17. Mowbray CT, McCrohan N, Bybee D: Integrating vocational services into case management: Implementation analysis of Project WINS. Journal of Vocational Rehabilitation 1995; 5:89-101. (Special issue on psychiatric disabilities)

18. Jonikas JA, Solomon ML, Cook JA: An inclusion framework: Preparing psychosocial rehabilitation programs and staff for the consumer hiring initiative. In: Mowbray CT, Moxley DP, Jasper C, Howell, L. (Eds.): Consumers as Providers in Psychiatric Rehabilitation. Columbia, MD: International Association of Psychosocial Rehabilitation Services, 1997, pp. 419-436. 